\title{
Las ciencias humanas: un horizonte de to- talidad para el teduccionismo científico. Denuncias y propuestas coincidentes en Ortega y Gasset y Paul Karl Feyerabend
}

\author{
Human Sciences: A Horizon of Totality for \\ Scientific Reductionism. Complaints and Pro- \\ posals matching in Ortega y Gasset and \\ Paul Karl Feyerabend
}

\author{
MARÍA TERESA GARGIULO \\ CONICET UnCuYo
}

Recibido: 23/02/2019 Aceptado:12/07/2020

\begin{abstract}
RESUMEN
Los diseños experimentales adoptados en las ciencias empíricas traducen y seleccionan exteriorizaciones fenoménicas, de modo tal que ellas constituyan ciertas formas de percepción y posibilidades de comprobación que procedan del «objeto» mismo. En un nivel meta-teórico, podríamos identificar en tales diseños reduccionismos que facilitan toda suerte de simplificaciones epistémicas y metodológicas a costa, de eliminar cosas que necesitan ser entendidas y que son parte de una imagen completa del fenómeno que estudiamos. Por reduccionismo entendemos el proceso de simplificación y operatividad que exige un diseño experimental. Pues bien, tanto Ortega y Gasset como Paul Karl Feyerabend denuncian las consecuencias y absurdos que se siguen de las diversas modalidades de reduccionesmo para la misma ciencia. No es novedad en absoluto reconocer en Ortega y Gasset un auténtico filósofo de la ciencia ni mucho menos
\end{abstract}

(C) Contrastes. Revista Internacional de Filosofía, vol. XXV No2 (2020), pp. 7-24. ISSN: 1136-4076

Departamento de Filosofía, Universidad de Málaga, Facultad de Filosofía y Letras Campus de Teatinos, E-29071 Málaga (España) 
encontrar afinidades con los grandes representantes de este campo disciplinar. En este trabajo analizaremos como las lecturas orteguianas de esta problemática, así como su propuesta, corre en líneas paralelas a las denuncias de Feyerabend.

PALABRAS CLAVE

ORTEGA Y GASSET, REDUCCIONISMO, CIENCIAS HUMANAS, PERSPECTIVISMO, FEYERABEND

\begin{abstract}
The experimental designs adopted in the empirical sciences translate and select phenomenal externalizations, so that they constitute certain forms of perception and verification possibilities that come from the «object» itself. On a meta-theoretical level, we could identify in such designs reductionisms that facilitate all kinds of epistemic and methodological simplifications at the expense of eliminating things that need to be understood and that are part of a complete picture of the phenomenon we study. By reductionism, we understand the process of simplification and operability that an experimental design demands. Well, both Ortega y Gasset and Paul Karl Feyerabend denounce the consequences and absurdities that follow the various forms of reductions for the same science. It is not new at all to recognize in Ortega y Gasset a true philosopher of science, much less find affinities with the great representatives of this disciplinary field. In this work we will analyze how the Orteguian readings of this problem, as well as its proposal, run in parallel to Feyerabend's complaints.
\end{abstract}

KEYWORDS

ORTEGA Y GASSET, REDUCTIONISM, HUMAN SCIENCES, PERSPECTIVISM, FEYERABEND

\title{
I. INTRODUCCIÓN
}

No eS NOVEDAD EN ABSOLUTO destacar a Ortega y Gasset como un auténtico filósofo de la ciencia. Ciertamente en diversas cuestiones medulares que componen este ámbito disciplinar, el español tiene algo que decir, y su aporte no es menor. Su legado como filósofo de la ciencia ha sido destacado por un número creciente de literatura. En orden a ser ilustrativos podemos citar, los estudios de Manuel Garrido (1983, p. 316) y Félix Martínez Bonati (2000, p. 7) quienes presentan a Ortega como un posmoderno que supo formular, aunque con distinto remate al de Kuhn y Foucault, los conceptos problemáticos de paradigma e inconmensurabilidad. Por otra parte, García Astrada, (1959) y Bueno (2001) presentan la filosofía de la ciencia orteguiana en línea con la tradición anti-positivista de Duhem, Poincaré y Weil. Mercedes Miquel (1992) tiene el mérito de encontrar en la obra del español la formulación de una fuerte crítica al proyecto positivista y racionalista de erigir un criterio de demarcación. En la distinción entre «comprensión» y «explicación científica» ella encuentra el eje sobre el cual Ortega establecería la diferenciación y retroalimentación entre las ciencias humanas y las ciencias naturales. También Pellicani (2007) 
traza líneas paralelas entre la obra de Popper y Ortega, aunque descuidando, a nuestro parecer, núcleos fundamentales de discrepancia ente ambos.

A modo de antecedente directo de nuestro estudio cabe citar el artículo de Ruiz Fernández (2013), donde expone las continuidades de la lectura orteguiana de la ciencia con la de Kuhn y particularmente con el anarquismo epistemológico y la proliferación teórica de Paul Karl Feyerabend. En continuidad con esta tradición de trabajo, nuestro estudio también busca prolongar y fortalecer esta línea de análisis que procura acercar la lectura orteguiana de la ciencia a las denuncias y propuestas de Paul Karl Feyerabend.

Atenderemos particularmente al tratamiento que hace el filósofo español respecto a los reduccionismos epistémicos y metodológicos que naturalmente son implementados en las ciencias naturales. Pero nuestro autor no se limita a señalar las consecuencias problemáticas de la implementación de los reduccionismos en la práctica científica sino que también apunta un camino que rescata el auténtico valor y las valiosas proyecciones de veracidad que suponen tales modelos. Señala a las ciencias del espíritu como la instancia donde aquellos diseños pueden encontrar auténtica resolución humana y científica; propuesta -que como veremos- encuentra sus paralelos en los escritos de Feyerabend.

Ciertamente, Ortega no abordó de forma sistemática y directa esta cuestión. De aquí que iremos extrayendo su tratamiento sobre la cuestión de diversos pasajes de sus escritos. En este sentido, nuestro estudio no busca respetar un orden estrictamente cronológico. La exposición será más bien hermenéutica y comprensiva.

Analizaremos dos tesis que, a nuestro entender, ilustran las dos caras fundamentales de la compresión de Ortega y Gasset respecto al alcance y los límites de los reduccionismos científicos y que representan una continuidad con los planteos y denuncias de Paul Karl Feyerabend. Primero, presentaremos - tanto en uno como en el otro- la tesis acerca del carácter relativo que posee toda teoría, modelo, diseño o explicación científica. Luego, expondremos la respectiva invitación del filósofo español y del epistemólogo vienés a resolver el valor cognoscitivo de tales diseños en la racionalidad propia de las ciencias humanas y metafísicas. Ambas tesis constituyen, a nuestro entender, una imagen completa de sus propuestas. La primera tesis no es sino un negativo fotográfico del proyecto que ambos tienen en vistas a enriquecer el quehacer científico.

II. RELATIVIZACIÓN DE TODA TEORÍA, MODELO O EXPLICACIÓN CIENTÍFICA

\section{I.1 LA LECTURA DE ORTEGA Y GASSET}

Ortega y Gasset supo explicitar el valor y peso cognoscitivo de los diseños físico matemáticos sin dejar por ello de explicitar el carácter reductivo 
que suponen. Por reduccionismo entendemos el proceso de simplificación y operatividad que exige un diseño experimental. Los diseños experimentales adoptados en las ciencias empíricas, y físico matemáticas traducen y seleccionan exteriorizaciones fenoménicas, de modo tal que ellas constituyan ciertas formas de percepción y posibilidades de comprobación que procedan del «objeto» mismo.

En su ensayo «La 'Filosofía de la Historia' de Hegel y la Historiología», Ortega (IV, p. 533) ${ }^{1}$ critica a la identificación moderna del método con la ciencia destacando el papel más bien subsidiario y contingente que poseen las metodologías en la práctica científica. Explica que el científico, entre una vasta variedad de técnicas y métodos, elige aquel que considera más apropiado según sea la naturaleza de su objeto. Las reglas y procedimientos metodológicos son el resultado de atender a la misma dinámica o contexto particular de cada investigación científica.

Ahora bien, esta relativización del método no le impide por ello dejar de destacar el carácter imprescindible que el método cumple en la empresa científica. El método cumple un papel secundario respecto al conocimiento del objeto que es lo que define de suyo la empresa científica. Más es ineludible en cuanto que todo conocimiento o resultado científico debe ser entendido y ponderado como la información que obtenemos de la realidad a través de un particular instrumento de observación, medición y análisis. El valor del conocimiento científico debe ser siempre ponderado y relativizado como el conocimiento obtenido a través de un método.

Los resultados obtenidos a través de la aplicación de un método no muestran sin más la realidad o la verdad de un fenómeno. Se trata de datos parciales que no son sino el resultado de dirigirle a la realidad una pregunta determinada. Es la información ontológica que ofrece la realidad física cuando ésta es inquirida por un determinado modelo o diseño experimental. El filósofo español expresa esta tesis de la siguiente manera:

[...] [L]a realidad no tiene una cara en sí, sino que la pone. Y a uno le pone una cara, y a otro le pone otra. La cara que aparece —el «fenómeno» de la fenomenología, la perspectiva - depende de los dos, de la realidad y de nosotros: «la pone ella pero nos la pone a nosotros. (IX, 370).

Esta tesis medular de su perspectivismo podría extrapolarse naturalmente a sus consideraciones respecto a la racionalidad físico-matemática. La faz que se nos muestre de la realidad dependerá en definitiva de nuestro modo de

1 Para las obras de Ortega citaremos haciendo referencia al tomo de las obras completas (Obras completas, Taurus, 2004-2010) en numeración latina seguido del número de página correspondiente. 
abordarla. La teoría que resulta validada por el diseño experimental no ni más ni menos que la respuesta que la realidad ha dado a una pregunta específica formulada a través de un particular método de observación y selección.

De alguna manera, el método y los instrumentos de medición condicionan el tipo de respuesta que obtendremos del fenómeno estudiado. Newton descubre leyes objetivas de la física como fruto de su extrapolación de la geometría euclídea. Einstein cambió la pregunta. Él estaba interesado en las propiedades del mundo físico macroscópico, aquel espacio que supera la velocidad de la luz. Y para estudiarlo tuvo que cambiar el método. Ya no resultaba válido, entonces -explica el filósofo español (II, 236)- acercase al espacio o la materia física desde la geometría euclídea puesto que en esa dimensión el espacio no tiene una estructura rectilínea, sino curva. Es el mundo de objetos, propiedades y sucesos por los que inquiere la pregunta científica, lo que justifica en definitiva una opción metodológica.

La relativización del método, así como sus tesis acerca del carácter relativo que tiene la información ontológica de todo diseño o modelo físicomatemático respecto a su método son dos tesis que ubican el realismo científico de Ortega como una solución intermedia entre el constructivismo y el objetivismo realista.

Ciertamente para el español en el conocimiento científico hay construcción la cual se despliega específicamente en la tarea de selección de variables, en la formulación de un método y en la postulación de un orden de inteligibilidad hipotético. Más estas tareas de análisis del sujeto no dejan por ello de obtener respuesta ontológica. La validación del conocimiento científico se fundamenta para nuestro autor justamente en esta referencia ontológica. En este sentido, creemos que Ortega está lejos del constructivismo duro que Gustavo Bueno (2001) y Luciano Pellicani (2007) pretenden adjudicarle.

En reiteradas ocasiones Ortega insiste que las teorías o modelos físicos no son simplemente el resultado de imponer a la realidad una forma «a priori». No se trata de un efecto puramente subjetivo. Ellos exhiben una cualidad objetiva de la realidad. Sus datos no son sino la cara que la realidad muestra a cada modelo: «es la cosa el maestro del hombre» (IX, 368)-escribe-. En este sentido y hay que dejarla a ella que hable y nos cuente su propia diaEn este sentido, hay que dejar que la realidad hable y nos cuente su propia dialéctica. Es decir que nos revele algunas de sus propiedades y leyes a través de los diseños experimentales con la que la inquirimos.

Pero Ortega también hace un esfuerzo concomitante por distanciarse de la ingenuidad del objetivismo realista. Las leyes de Newton, las leyes electromagnéticas de Maxwell; la ecuación cuántica de Schrödinger ciertamente seleccionan, de un modo u otro, un cierto número de elementos. La función de estos diseños es claramente selectiva. De la infinitud de 
propiedades, sucesos y elementos que integran la realidad física, inquieren únicamente por un cierto número de ellas. «Las demás cosas - fenómenos, hechos, verdades - quedan fuera, ignoradas, no percibidas», escribe Ortega en El tema de nuestro tiempo (III, 198). Vale la pena detenerse en el siguiente texto donde el español explicita lo que él entiende por esta tarea de selección y construcción del científico:

Así, por ejemplo: los cuerpos lanzados se mueven de innumerables maneras, suben, bajan, siguen en su trayecto las curvas mas diversas, con las más distintas velocidades. En tan inmensa variedad nos perdemos y por muchas observaciones que hagamos sobre los hechos del movimiento no lograremos descubrir el verdadero ser del movimiento. ¿Qué hace, en cambio, Galileo? En vez de perderse en la selva de los hechos entrando en ellos como pasivo espectador, comienza por imaginar la génesis del movimiento en los cuerpos (...) Comienza por construir idealmente, mentalmente, una realidad. Sólo cuando ya tiene lista su imaginaria realidad observa los hechos, mejor dicho, observa qué relación guardan los hechos con la imaginada realidad (V, 16-17).

Esta tarea de selección, reducción y simplificación que emprende el científico es lo que establece las coordenadas desde las cuales debe ponderarse la relativa validez de un modelo. El experimento no ofrece, sin más, la faz de la realidad. Sus datos no manifiestan realidad absoluta alguna. Exhiben el resultado de una interacción: por un lado una realidad que responde o manifiesta determinadas propiedades, por otro, los limitados instrumentos de medición y selección con los que se la inquiere. Lo que los experimentos confirman es una posible adecuación o correspondencia entre el hipotético orden postulado por la teoría y el orden en que se manifiestan los fenómenos -explica el español (IV, 528)-.

Mostrando el absurdo de la «idolatría del experimento» Ortega y Gasset (VIII, 257) busca matizar la postura del objetivismo realista. El experimento, en primer lugar, devela únicamente aquellas propiedades que son susceptibles de ser traducidas por el método de investigación adoptado. Segundo, los resultados obtenidos a partir de él en absoluto reflejan la abundancia de lo real, es decir, la realidad cambiante y diversa de nuestra vida. Pensar lo contrario sería propio de una actitud «provincialista»-explica el filósofo español (II, p. 234)- es decir, una actitud análoga a la de aquellos individuos que, al no haber salido nunca de su localidad, creen que el mundo se reduce a ella, o, al menos, interpretan la diversidad del mundo desde los parámetros de su pequeña ciudad.

A partir de estos análisis Ortega procura fundamentar su comprensión de la razón físico-matemática, y podríamos decir de la racionalidad científica en general, como una «razón circunstancial». Se trata de una racionalidad 
que debe entenderse en función de las circunstancias metodológicas concretas desde la cual se enfrenta, se aborda, si inquiere acerca de la realidad. Los resultados obtenidos a través de un método no pueden erigirse por sí mismos como la verdad total, absoluta y definitiva. Una racionalidad contextual sabe dar cuenta de sí misma a partir de las circunstancias, premisas, y procesos que la condujeron a una serie de aserciones.

\section{I.2 LA LECTURA DE FEYERABEND}

En el devenir intelectual de Paul Karl Feyerabend también encontramos consideraciones análogas respecto a las consecuencias absurdas que se siguen del reduccionismo metodológico para la racionalidad científica. En las sucesivas publicaciones de su Tratado contra el método fue madurando su crítica contra una racionalidad científica que pretende erigir el método como lo absoluto, o que ha identificado la ciencia con el método.

A la pretensión del positivismo lógico y del racionalismo crítico de resguardar la racionalidad y la objetividad científica apelando a ciertas exigencias metodológicas, Feyerabend le opone su teoría anarquista del conocimiento que muestra cómo todas las metodologías tienen sus límites. Si el racionalista quiere un principio universal aplicable bajo cualquier circunstancia, el único criterio que tiene para ofrecerle -dirá Feyerabend con su ironía característica- es el principio «todo vale». Por cierto, un principio vacío e inútil pero capaz de satisfacer las exigencias de un racionalista. El «todo vale» no es sino un jocoso e irónico resumen de la sorpresa de un racionalista al descubrir la ausencia de un criterio metodológico universalmente aplicable a la ciencia. En La ciencia en una sociedad libre, escribe:

De lo único que se dan cuenta es de mis resúmenes un tanto irónicos; la única manifestación positiva que encuentran -y que inmediatamente eringe en 'tesis central' o 'principio' de la 'metodología de PKF' - es la consigna 'todo vale'. Pero 'todo vale' no expresa ninguna convicción mía, sino que es un compendio jocoso de los apuros del racionalista: si quieres criterios universales -digo-, si no puedes vivir sin principios cuya valides esté por encima de la situación, la forma del mundo, las exigencias de la investigación y las peculiaridades temperamentales, entonces yo te proporciono uno de estos principios. Será vació, inútil y bastante ridículo, pero será un 'principio'. Será el 'principio' 'todo vale'. (Feyerabend, 1978/1982, p. 223). ${ }^{2}$

2 Para facilitar la lectura, las citas de algunas obras de Paul Feyerabend tendrán doble fecha. Se hará en el caso de que se trate de una obra cuya edición original haya sido corregida, ampliada o reeditada. La primera se refiere al año de la primera publicación y la segunda a la publicación consultada. El objetivo de la doble fecha es dar cuenta de un orden cronológico de 
Por reducción al absurdo el vienés pretende mostrar al absurdo las contradicciones y paradojas en las que incurre un racionalista o un positivista lógico al intentar definir la ciencia por un método. Presenta las incoherencias que supone el intento de entender, definir y fundamentar en el método la objetividad o la racionalidad científica.

Resulta claro, pues, que la idea de un método fijo, o la idea de una teoría fija de la racionalidad, descansa sobre una concepción excesivamente ingenua del hombre y de su contorno social. A quienes consideren el rico material que proporciona la historia, y no intenten empobrecerlo para dar satisfacción a sus más bajos instintos y a su deseo de seguridad intelectual con el pretexto de claridad, precisión, 'objetividad', 'verdad', a esas personas les parecerá que sólo hay un principio que puede defenderse bajo cualquier circunstancia y en todas las etapas del desarrollo humano. Me refiero al principio todo sirve (Feyerabend, 1975/1992, p. 12).

Feyerabend (1972/1999, p. 180) no impugna las reglas metodológicas en cuanto tales. Se opone únicamente al carácter universal, absoluto o comprehensivo que le conceden -según el vienés- la gran mayoría de los epistemólogos de la ciencia. Las reglas y procedimientos metodológicos son resultado de atender a la misma dinámica o contexto particular de cada investigación científica. Presenta su anarquismo en oposición a todo estándar de investigación trascendental. Argumenta que siempre existen circunstancias que obligan no sólo a ignorar las escrupulosas y rígidas restricciones del método científico sino incluso a adoptar lo opuesto. En virtud de este anarquismo el científico -atendiendo a las circunstancia concretas de su investigación-puede preferir ciertos procedimientos en lugar de otros. Pero tal preferencia nunca se convertirá en un principio universal y objetivo que justifique la racionalidad de la tarea científica:

Al tratar de resolver un problema, los científicos utilizan indistintamente un procedimiento u otro: adoptan sus métodos y modelos al problema en cuestión, en vez de considerarlos como condiciones rígidamente establecidas para cada solución. No hay una 'racionalidad científica' que pueda considerarse como guía para cada investigación; pero hay normas obtenidas de experiencias anteriores, sugerencias heurísticas, concepciones del mundo, disparates metafísicos, restos y fragmentos de teorías abandonadas, y de todos ellos hará uso el científico en su investigación. Por supuesto esto no quiere decir que no sean posibles unas teorías racionales que faciliten modelos sencillos para la resolución de problemas científicos: de hecho, existen, y algunos incluso alcanzan a ser tomados en cuenta en algunas investigaciones, pero pretender que son la base de toda la ciencia sería

las publicaciones y, al mismo tiempo, remitir el lector a los lugares precisos donde pueda cotejar las citas textuales, las paráfrasis y las referencias generales. 
lo mismo que pretender que los pasos del ballet clásico son la base de toda la locomoción. No tiene sentido formular, de una forma general y al margen de los problemas específicos, cuestiones tales como 'qué criterio seguiría para preferir una teoría a otra', y sólo podrían responder de forma concreta aquellos que han tenido que resolver problemas específicos y que utilizan los conocimientos (en gran medida intuitivos) que han acumulado en estos procesos para poder hacer sugerencias definidas (Feyerabend, 1975/1992, pp. xv-xvi).

En la misma línea que el filósofo español, el vienés (1991, p. 62) explica que la ciencia no puede ser juzgada a la luz de ciertas reglas epistemológicas abstractas e independientes de las circunstancias en las que cada investigación se realiza; a menos que éstas sean el resultado de una práctica epistemológica especial en continua evolución. Prescribir de ante mano reglas metodológicas para el movimiento científico no es sino un necio intento de construir un instrumento de medida sin considerar lo que se va a medir y en qué circunstancias (Feyerabend, 1978/1982, p. 238).

Feyerabend trasciende la discusión acerca de la relación que cada teoría o modelo establece con su método, tal como es planteada en el marco de una epistemología normativa o descriptiva de la ciencia. Sus críticas y denuncias no tienen como objeto el método en cuanto tal sino la misma noción de ciencia. La cuestión que se le presenta por resolver no es cuál es el método más eficaz o cuál es el que emplea habitualmente el científico sino qué es ciencia. El vienés denuncia que la filosofía de la ciencia, tal como se desarrolló a lo largo del siglo XX, ha sido incapaz de ofrecer una clara noción de ciencia. Pues si el método es lo que define a la ciencia, y existe una pluralidad de métodos, se debe admitir que existe una infinidad de modos de entender la ciencia. $\mathrm{O}$, en otras palabras, dada la identidad establecida por el racionalismo crítico entre ciencia y método, el anarquismo metodológico obliga a reconocer la ausencia de una definición que explique qué es ciencia:

¿Qué es la ciencia? ¿Cómo proceden los científicos? ¿En qué se diferencian sus normas de las normas de otras empresas? [...]

Mi respuesta a la primera cuestión es que la amplia divergencia de individuos, escuelas, períodos históricos, ciencias enteras hacen extremadamente difícil identificar principios comprensivos relativos a métodos, o a hechos. La palabra 'ciencia' no es más que una palabra- pero no hay una única entidad que se corresponde con aquella palabra (Feyerabend, 1993/2008, p. 238).

Feyerabend no busca simplemente remplazar aquella visión racionalista de la ciencia por la antítesis del «todo vale». Lo que pretende es despertar un debate en torno al cual pueda generarse, a modo de una nueva síntesis, una filosofía de la ciencia más sensible a las complejidades y contingencias 
históricas de la ciencia. Su anarquismo no puede ser entendido sino como una respuesta al racionalismo y como los inicios de una búsqueda de una explicación más justa de la ciencia.

Al final de su vida, Feyerabend se ocupa de formular una metafísica que le permita alejarse del relativismo y de la visión constructivista de ciencia que se le adjudicaba. Procura distanciarse de esta visión relativista con un esfuerzo análogo al que constatamos en el perspectivismo del filósofo español.

Adoptando un lenguaje metafísico postula una entidad que aunque puede ser manifestada o expresada parcialmente por una multiplicidad de culturas, teorías, modelos o diseños metodológicos, subraya, que ninguna de ellas puede dar cuenta acabada de su abundancia (Cf. Feyerabend 1987/2005, pp. 70 y $78 ; 1991 / 2003$, pp. 152-153; 1994/2000, pp. 23, 33, 37 y 169). En su obra póstuma sobre La conquista de la abundancia (1994/2000), p. 173) explica que este Ser, mundo, Dios o materia responde positiva o negativamente a los interrogantes de la ciencia y la cultura. En otro pasaje, escribe:

[...] [O]tros importan el término 'relativismo' y me lo aplican. Pero todavía les puedo corregir de la siguiente manera.

Para empezar, no todas las formas de abordar la 'realidad' tienen éxito. Como ocurre con las mutaciones inadaptadas, algunos enfoques sobreviven durante un tiempo -sus agentes sufren, muchos mueren- y, entonces, desaparecen. Así, la mera existencia de una sociedad con ciertos modos de conducta y ciertos criterios para juzgar lo que se ha conseguido no es suficiente para establecer una realidad manifiesta, también hace falta que Dios, el Ser, o la Realidad Básica, reaccione de un modo positivo. Sea lo que sea, el relativismo que aparece en este artículo no es, por lo tanto, una posición filosófica, sino un hecho empírico que recibe el apoyo de una multiplicidad de enfoques y resultados procedentes de muchos campos distintos (Feyerabend, 1994/2000, pp. 253-254).

Esta resistencia o aprobación del Ser es justamente lo que no tienen en cuenta los constructivistas o relativistas. Para un relativista o constructivista toda proyección es válida. Los resultados que se siguen, por ejemplo, de la aplicación de un diseño metodológico no pueden ser considerados sin más como verdaderos. «No todas las proyecciones son exitosas»-escribe Feyerabend (1994/2000, p. 168)- pues la naturaleza o el Ser «no es algo amorfo a lo que se le pueda dar cualquier forma. Resiste y mediante su resistencia revela sus propiedades y leyes» (Feyerabend 1994/2000, p. 280).

En pocas palabras, una de las líneas paralelas fundamentales que atraviesa tanto el perspectivismo del español como el anarquismo de Feyerabend es su común comprensión de la racionalidad científica como una racionalidad contextual o «circunstancial». Es decir, una racionalidad que es inherentemente dependiente de las circunstancias metodológicas, históricas y culturales 
concretas desde las cuales ella inquiere acerca de la realidad. Aunque cabe insistir que en ambos existe también el esfuerzo por alejar, tanto en un orden metafísico como metodológico, la inscripción de esta comprensión de la racionalidad científica dentro de los límites de un constructivismo social.

Tal como veremos en el próximo punto, este carácter contextual y reductivo del quehacer científico- es comprendido y analizado, por uno y otro autor, en la medida que explicitan la relación que cada teoría o modelo posee respecto a las ciencias humanas y metafísicas. De un modo u otro, ambos postulan las ciencias humanas como el espacio o la dimensión donde la ciencia adquiere o resuelve su carácter propiamente cognoscitivo.

\section{LAS CIENCIAS DEL ESPÍRITU, INSTANCIA RESOLUTIVA DE LA CIENCIA}

\section{1 LA LECTURA ORTEGUIANA}

Demos un paso más en el análisis de la propuesta orteguiana para la ciencia. El español escribe: «la ciencia empieza donde el método acaba» (IV, 533). Ahora, cuando acaba la postulación, la selección, la aplicación, el seguimiento y el control de un método ¿qué sigue? Pues sigue la instancia propiamente científica, a saber, la tarea de comprensión a la que solo se puede acceder a través de la racionalidad histórica de las ciencias humanas.

Cuando Ortega se refiere a la «Historia» o a la «razón histórica» en sus ensayos -tal como explica Mercedes Miquel (1992, p. 147)- no se refiere a una disciplina particular como puede ser la historiografía. Con ellos se refiere a una particular forma de racionalidad que comparte el conjunto de las ciencias humanas. El español establece explícitamente una sinonimia cuando escribe: «la Historia, es decir, las ciencias de lo humano» (VI, 185). De aquí que nos hemos permitido la libertad de hablar en general de la racionalidad propia de las ciencias humanas.

La racionalidad en la que se despliegan las ciencias humanas devuelve a la razón físico-matemática la conciencia del proceso a partir del cual ella se ha ido gestando (vol. VI, 50). Ortega (V, 67) utiliza la noción de «altura de los tiempos» para denominar esta perspectiva histórica que las ciencias empíricas adquieren en virtud de su participación en la ciencias del espíritu. Esta dimensión histórica es lo que otorga proporción y magnitud a cada uno de los diseños en el todo del conocimiento humano. Posibilita el progreso en la medida que le permite al científico percibir la limitación de un hallazgo, sea para corregirlo y completarlo, o bien para negarlo y objetarlo (IX, 5199).

Las ciencias humanas contextualizan el conocimiento científico en su desarrollo humano. Ellas cuentan su historia (VI, 40). Trascienden la discontinuidad fragmentaria de cada teoría para entender el proceso que 
explica su unidad integradora. Disciernen el horizonte teológico, cosmológico y moral a partir del cual han fluido las teorías. Por ellas, los diversos modelos físico-matemáticos conforman un sistema significativo de la realidad que revela las implicancias existenciales de sus horizontes teóricos.

Si el todo es más grande que las partes, las ciencias humanas parecerían tener el mérito de integrar y explicar la continuidad de las partes en el todo argumenta en «Ditthey y la Idea de la Vida». En pocas palabras, son las ciencias humanas las que facilitan el camino hacia la unidad del saber (VI, 185).

Así como Ortega se esforzó por alejar su comprensión de la ciencia del constructivismo social; de modo análogo destaca el peso ontológico que fundamenta al método hermenéutico de las ciencias históricas: «La Historia no es manipulación, sino descubrimiento de realidades: aletheia», escribe (IV, 532.). Las ciencias humanas comprenden el peso de las cosas según lo que ellas significan en la vida de los hombres. Para ellas «explicar algo es, en última instancia, mostrar su lugar y papel dentro de la economía viviente de nuestra conciencia» (VI, 212). El filósofo rescata la dimensión teológica, cultural y espiritual desde la cual y en la cual necesariamente se vivencian los objetos de estudio. Dichas dimensiones son las que explican los hechos, los seres y sucesos tal como son aprehendidos en nuestras vivencias originarias. O dicho en otros términos, la vida es la fuente originaria del sentido de los hechos que no es sino el objeto de las ciencias humanas. El verdadero ser de las cosas solo puede ser aprehendido en la vivencia originaria que ellas revelan.

Por esta tarea hermenéutica las ciencias históricas acceden al sentido de los hechos y por ello son éstas las que cumplen propiamente, según el español, la instancia propiamente resolutiva de la ciencia. Pues si la ciencia no es sino alcanzar el verdadero ser de las cosas, y éste no se revela sino en las experiencias vitales aprehendidas por las ciencias humanas, serán estas las que propiamente se les puede reconocer el estatuto de ciencias.

\section{2 LA LECTURA DE FEYERABEND}

En los escritos de Feyerabend podemos encontrar una lectura o análisis análogo respecto a las ciencias humanas. Aunque él no va a hablar de ciencias humanas sino de lo que sus interlocutores reconocen como instancias metafísicas, pre-científicas o pseudo-científicas. El vienés postula que aquellos elementos que el positivismo lógico reconoce como pseudo-científicos, o aquellos que el racionalismo crítico de Popper identifica como pre-científicos o pre-racionales constituyen el corazón de la misma ciencia.

Entre el 55 y 68 Feyerabend (1960/1981, pp. 42-43). utiliza frecuentemente la noción de 'metafísica' en el sentido popperiano, es decir, para referirse a todo aquello que no puede ser objeto de falsación empírica. En este sentido, una 
teoría será metafísica en la medida que no sea posible especificar un resultado experimental que pueda ponerla en peligro u obligarnos a abandonarla. Además de esta referencia a la concepción popperiana de metafísica, el epistemólogo (1962/1989, pp. 17 y 40; 1970/1989, pp. 140-141) con la noción de metafísica se refiere, en un marco más general, a todos aquellos elementos que no son susceptibles de comprobación empírica y en este sentido coincide con lo que el positivismo lógico, en general, entiende por metafísica.

Feyerabend no asume estas comprensiones de la metafísica como una tesis propia sino en orden a llevar cabo una reducción al absurdo de las mismas, es decir, con el fin de mostrar la contradicción intrínseca que éstas suponen. Le interesa demostrar la paradoja por la cual todos aquellos elementos que el positivismo lógico o el racionalismo crítico considera como carentes de sentido - pues no pueden ser criticados y desarrollados según sus 'cánones de racionalidad científica' - constituyen la materia que fecunda la tarea científica.

En un sentido positivo, Feyerabend prefiere hablar no ya de metafísica sino de ontología. Con ella se refiere a las visiones del mundo que informan la actividad científica. Reconoce como ontológico a todo sistema conceptual comprehensivo lo suficientemente rico como para esbozar una explicación de la totalidad de las apariencias físicas y, por tanto, capaz de sustituir a las demás cosmovisiones como un todo (Feyerabend, 1958, pp. 78-79, 90-91; $1961 / 1999$, pp. $52-54 ; 1962 / 1981$, p. $323 ; 1962 / 1989$, pp. 38, 77-78, 137-138; 1965/1981, pp. 109-110; 1967, p. 40; 1975/1992, pp. 102-103).

Feyerabend postula la necesidad de acceder a una visión comprehensiva de la ciencia que entienda el carácter resolutivo que los elementos metafísicos poseen en el seno del quehacer científico. En este sentido le interesa demostrar la vacuidad de los diversos criterios que han introducido los filósofos de la ciencia:

Combinando esta observación con la idea de que la ciencia no posee ningún método particular, llegamos a la conclusión de que la separación de ciencia y no ciencia no sólo es artificial, sino que va en perjuicio del avance del conocimiento. Si deseamos comprender la naturaleza, si deseamos dominar nuestro contorno físico, entonces hemos de hacer uso de todas las ideas, de todos los métodos, y no de una pequeña selección de ellos. La afirmación de que no existe conocimiento alguno fuera de la ciencia — extra scientiam nulla salus - no es más que otro cuento de hada interesado (Feyerabend, 1975/1992, p. 301).

Feyerabend no pretende negar la racionalidad científica en cuanto tal. Le interesa mostrar que aquellos elementos metafísicos que sus interlocutores pretenden excluir del ámbito científico constituyen el eje sobre el cual se desarrolla la práctica científica. En virtud de los elementos ontológicos una teoría o modelo define un modo particular de ver la realidad, estable una manera 
de seleccionar disponer y explicar la evidencia o hechos observacionales, fija la significación que adquieren los términos teóricos y observacionales, crea los instrumentos de observación y medición, y codifica los modos en que los resultados deben interpretarse (Feyerabend, (1962/1989, p. 108, 53-54, 7778).

Ahora bien, la adhesión a tales supuestos ontológicos no es simplemente -argumenta- 'un salto en el vació' sino que obedecen a una racionalidad contextual de la que es incapaz de dar cuenta tanto el racionalista como el positivista lógico:

No niego que se puedan trazar líneas de demarcación entre las diferentes actividades. Lo que niego es que exista una gran línea divisoria entre las ciencias y las artes. Respecto a la cuestión de los descubrimientos y las justificaciones, ya di mi opinión cuando hable de los experimentos: el proceso que lleva a aceptar los resultados de un experimento está rodeado de elementos personales y modos de ser colectivos, exactamente lo mismo que ocurre con los descubrimientos. De hecho, la dicotomía entre descubrimiento y justificación es más bien irreal. El 'descubrimiento' nunca es un salto en el vacío o un sueño; interviene también una buena porción de razonamiento. Y la 'justificación' nunca es un proceso completamente 'objetivo' -intervienen muchos elementos personales. [...] Si yo fuese aficionado a las generalizaciones como tú, diría que la vieja distinción entre ciencias físicas y ciencias sociales (incluidas las disciplinas humanísticas) es una distinción que no responde a ninguna diferencia -todas las ciencias son ciencias humanas y de todas las ciencias humanas se derivan conocimientos (Feyerabend, 1989/2000, pp. 144-145).

Cada episodio particular de la historia de la ciencia es racional en el sentido que sus rasgos pueden ser explicados en los términos de una racionalidad elaborada y reconocida justamente en virtud de sus elementos metafísicos (Feyerabend, 1993/2008, p, 237). De época en época, y como resultado de múltiples acercamientos metafísicos al mundo físico, se formulan diversos modelos de racionalidad científica (Feyerabend, 1972/1999, pp. 171-172). En este sentido, Feyerabend no describe las disputas entre Galileo y la Iglesia como el enfrentamiento de la racionalidad científica contra la irracionalidad sino más bien, como una controversia entre diversos criterios de racionalidad:

Preguntémonos entonces: ¿podemos imaginar que después de haber oído hablar de Copérnico esa gente aún permaneciera ligada a sus concepciones? Sí. ¿Podemos imaginar que justificaron su actitud con razones propias? Sí. ¿Qué tipo de razones podían aludir? Una fuerte creencia en la verdad literal de la importancia de la forma del viaje de Cristo. ¿Es 'irracional' esta creencia cuando 
se la compara con los argumentos 'científicos'? Es 'irracional' si se la compara con las reacciones 'normales' de los partidarios del progreso, los cuales, sin embargo, son tan precarias como las reacciones normales del público de un mago. No es irracional cuando se tiene en cuenta la naturaleza de las concepciones del mundo. Esta naturaleza permite que cada grupo permanezca fiel a sus creencias cuando quiera y la situación política no se lo impida.

[...] ¿fue 'racional' la decisión de la Iglesia?

Depende de los criterios de racionalidad que escojamos (Feyerabend, 1996/1999, p. 85).

A nuestro epistemólogo vienés le interesa destacar sobre todo que los criterios de racionalidad que ofrecen los filósofos de la ciencia del siglo XX son insuficientes para explicar todos los rasgos importantes de un episodio particular. Para acceder a una imagen completa de la ciencia deben considerarse -explica Feyerabend (1970/1989, pp. 101-102)- aquellos factores y aspectos que son excluidos por tales criterios. Por ejemplo, a través de un estudio de la revolución copernicana Feyerabend busca mostrar como la complejidad del quehacer científico resiste a todo intento de definir la ciencia delimitándola de los elementos míticos, teológicos o metafísicos. Ningún episodio de la historia de la ciencia se adecúa a las reconstrucciones racionales que ofrecen el empirismo, el positivismo lógico, el falsacionismo, el convencionalismo o los programas de investigación de Lakatos. Por el contrario, Feyerabend (1993/2008, pp. 136-138) demuestra que las argumentaciones de Copérnico y de Galileo - con las que procuraban demostrar su modelo astronómicotraían a colación problemas de carácter epistémico, cosmológico y teológico que no son atendidos por los modelos de racionalidad mencionados pero que sí estaban en consonancia con el modelo de racionalidad vigente en aquel entonces.

Pero el epistemólogo vienés no solo insiste que los supuestos metafísicos son en definitiva el núcleo medular capaz de dar cuenta de los diversos modelo de racionalidad científica. También asegura que la revisión crítica de este espacio metafísico de la ciencia puede constituir un camino para que ella recupere su lugar dentro una imagen humanista de la ciencia.

A lo largo de toda su obra- Feyerabend denuncia que la ciencia ha devenido en una empresa que con pretensión de autosuficiencia ha relegado las visiones del mundo - capaces de satisfacer los interrogantes más propios del hombre- al campo de las humanidades, o lo que lo mismo al ámbito de lo no-científico. De este modo, la ciencia abandona su obligación primigenia de ofrecer lo que Evandro Agazzi (1978, 62-66) entiende como «conferimiento de sentido». El racionalismo que atraviesa a la ciencia contemporánea no es sino para el vienés el fruto de una larga tradición occidental que en aras de alcanzar un conocimiento objetivo ha impuesto una «renuncia ascética de 
todo alimento espiritual» (Feyerabend, 1994/2000, p. 26), cerrando así toda posibilidad de hacer de la ciencia una empresa más humana. El naturalismo cientificista -escribe el vienés- «sólo proporciona una parte de lo necesario para una vida completa [pues] al afirmar que no existe nada más [que la materia] vacía el mundo de sentido» (Feyerabend, 1991/2003, p. 116).

Feyerabend destaca la dimensión humana como un aspecto fundamental que definía originariamente a la ciencia y que es necesario recuperar. En aras a poder formular un modelo de racionalidad más complejo y humano señala la vacuidad de las dicotomías establecidas por el positivismo y el racionalismo entre ciencia y metafísica. Bajo diversas terminologías y locuciones, según sean sus interlocutores, Feyerabend invita a repensar el quehacer científico en y desde los parámetros de las ciencias humanas o metafísicas. Ellas permiten evaluar los logros del materialismo cientificista y repensar la ciencia contemporánea como una tarea cognoscitiva más atenta a las implicancias humanas y existenciales de sus teorías y modelos (Feyerabend 1987/2005, p.14).

Sitúa lo humano como uno de los valores epistémicos supremos en virtud del cual deben ser juzgadas y valoradas las tradiciones de pensamiento, entre ellas la misma ciencia, con sus respectivos mundos de sentido. En Consuelos para un especialista escribe: «¿Qué valores elegiremos para poner a prueba las ciencias de hoy? A mí me parece que la felicidad y el completo desarrollo del ser humano individual sigue siendo el valor más alto posible» (Feyerabend 1970/1981, p. 143).

Por humano el vienés entiende el contenido vivencial y el bienestar que ofrece una teoría o cultura. Y cuando habla de bienestar no se refiere al bienestar físico, sino el bienestar en el cual se obtiene, entre otras cosas el completo desarrollo de las facultades humanas y la felicidad espiritual. Bienestar no es un estado de placer y comodidad que la sociedad puede disponer, por ejemplo, a través de los desarrollos tecnológicos. El bienestar es estar en el bien, ser en el bien, de modo tal que este bien nos plenifique. ${ }^{3}$ Pues bien la ciencia occidental contemporánea debe ser juzgada según este criterio de bienestar.

Pues bien, en esta invitación del vienés encontramos nuevamente una profunda afinidad conceptual con el filósofo español. Uno y otro conciben las ciencias humanas y metafísicas, como el espacio o la dimensión, capaz de revelar el contenido vivencial de una cultura; una cultura que no es sino una manifestación parcial del mundo y la naturaleza humana. En este sentido, ellas constituyen el camino cognoscitivo que permite juzgar en perspectiva los

3 Parafraseando el ensayo de Mill sobre la Libertad humana el vienés define el bienestar como el desarrollo pleno de las facultades humanas. Esta idea se puede ver en Feyerabend (1999, p. 77) 
límites y logros de las diversas modalidades de reduccionismo metodológico adoptadas en el quehacer científico.

\section{REFERENCIAS BIBLIOGRÁFICAS}

AGAZZI, Evandro.1978: Temas y problemas de Filosofía de la Física. Barcelona: Herder.

BUENO, Gustavo. 2001: «La idea de ciencia en Ortega», El Basilisco, 31, pp.15-30.

FEYERABEND, Paul. 1958: «Complementarity». Proceedings of Aristotelian Society, Suppl. Vol. 32, pp. 75-104.

. 1960/1981: «On the Interpretation of scientific theories». Realism, rationalism and scientific method, Philosophical Papers Volume 1. Cambridge, Cambridge University Press, pp. 37-43.

. 1961/1999: «Knowledge without foundation». Paul K. Feyerabend: Knowledge, Science and Relativism, Philosophical Papers Volume 3, John Preston (ed.). Cambridge, Cambridge University Press, pp. 50-77.

. 1962/1981: «Hidden variables and the argument of Einstein, Podolsky and Rosen». Realism, rationalism and scientific method, Philosophical Papers Volume 1. Cambridge, Cambridge University Press, pp. 298-342.

. 1962/1989: Límites de la ciencia. Explicación, reducción y empirismo. Barcelona, Paidós.

. 1965/1981: «Reply to Criticism. Comments on Smart, Sellars and Putnam». En Realism, rationalism and scientific method, Philosophical Papers Volume 1. Cambridge, Cambridge University Press, pp. 104-131.

. 1967: «The Mind-Body Problem». Continuum 5, pp. 35-49.

1970/1981: «Consolations for the Specialist». Problems of Empiricism. Philosophical Papers Volume 2. Cambridge, Cambridge University Press, pp. 131-167.

. 1970/1989: Contra el método. Esquema de una teoría anarquista del conocimiento. Barcelona: Ariel.

. 1972/1999: «On the Limited Validity of Methodological Rules». En Knowledge, Science and Relativism. Philosophical Papers. Volume 3. By Paul Karl Feyerabend. John Preston (ed.). Cambridge: Cambridge University Press, pp. 138-180.

- 1975/1992: Tratado contra el método: esquema de una teoría anarquista del conocimiento. Diego Ribes (trad.). Madrid: Tecnos.

. 1978/1982: La ciencia en una sociedad libre. Alberto Elena (trad.). Madrid: Siglo XXI, 1987/2005: Adiós a la razón. José R. de Rivera (trad.). Madrid: Técnos. 1989/2000: Diálogos sobre el método. 2a ed. Madrid: Cátedra.

1991: Diálogos sobre el conocimiento. Jeronima Garcia Bonafe (trad.). Madrid: Cátedra.

. 1991/2003: Provocaciones filosóficas. Ana P. Esteve Fernández (trad.). Madrid: Biblioteca Nueva. 
. 1993/2008: Against Method. London: Verso.

1994/2000: La conquista de la abundancia: la abstracción frente a la riqueza del ser. Radamés Molina y César Mora (trads.), Barcelona: Paidós. . 1996/1999. Ambigüedad y Armonía. Barcelona: Paidós.

GARCÍA ASTRADA, Arturo. 1959: «Teoría de la ciencia en Ortega», Revista de la Facultad de Filosofía y Letras, 12, pp. 57-78.

GARRIDO, Manuel. 1983: «El yo y la circunstancia», Teorema, XIII, 3:4, pp. 309343.

MIQUEL, Mercedes. 1992: «Filosofía de la Ciencia en Ortega y Gasset Ciencias Naturales y Humanas: hacia una demarcación», Logos. Anales del Seminario de Metafísica. Núm. Extra. Homenaje a 5. Ráhade. Ed. Complutense, pp. 127-154.

MARTÍNEZ BONATI, Félix. 2000: «El postmodernismo de Ortega y Gasset», Mester, 29, pp. 1-27.

ORTEGA Y GASSET, José. 2004-2010: Obras Completas. Tomos I-X. Madrid: Taurus.

PELLICANI, Luciano. 2007: «Ortega y Popper: trayectorias paralelas», Revista de Occidente, 312, pp. 35-56.

RUIZ FERNÁNDEZ, Jesús. 2013: «Ortega y Gasset, filósofo de la ciencia», ÉNDOXA: Series Filosóficas, 31, pp. 109-126.

Teresa Gargiulo es Doctora en Filosofía por la Universidad Nacional de Cuyo, Argentina. Es Investigadora de CONICET (Consejo Nacional de Investigaciones Científicas y Técnicas)

Líneas de Investigación:

Paul Feyerabend, criterios de demarcación, inconmensurabilidad, ciencia y metafísica, teorías de la justificación epistémica

Publicaciones recientes:

(2020). «Los límites de la racionalidad científica frente al fenómeno de la espiritualidad: una revisión epistemológica de los reduccionismos metodológicos en la investigación psicoclínica», Scio n. ${ }^{\circ}$ 18, Julio de 2020, 261-294. https://doi. org/10.5093/rhp2020a4.

(2019). «¿Existe en Aristóteles el problema de la inconmensurabilidad? Un análisis desde la doctrina y la hermenéutica de Paul Karl Feyerabend», Acta Philosophica Vol, 28 (2019), fasc. 1, pp. 35-56.

Correo electrónico: gargiulomteresa@gmail.com 